\title{
TLR4-mediated NF- $\kappa B$ signaling pathway mediates HMGB1-induced pancreatic injury in mice with severe acute pancreatitis
}

\author{
GANG LI, XUEJUN WU, LE YANG, YUXIANG HE, YANG LIU, XING JIN and HAI YUAN
}

Department of Vascular Surgery, Shandong Provincial Hospital

Affiliated to Shandong University, Jinan, Shandong 250021, P.R. China

Received May 3, 2015; Accepted November 11, 2015

DOI: $10.3892 /$ ijmm.2015.2410

\begin{abstract}
Severe acute pancreatitis (SAP) is an extremely dangerous acute abdominal disorder which causes multiple complications and has a high mortality rate. Previous research has suggested that high-mobility group box 1 (HMGB1) plays an important role in the pathogenesis of SAP; however, the mechanisms underlying this strong correlation remain unclear. In this study, to further investigate whether HMGB1 acts as a stimulating factor, and whether Toll-like receptor 4 (TLR4) acts as its major mediator in the development of pancreatic injury during SAP, recombinant human HMGB1 (rhHMGB1) and TLR4-deficient mice were used. We found that HMGB1 and TLR4 were highly expressed, and nuclear factor- $\mathrm{\kappa B}(\mathrm{NF}-\kappa \mathrm{B})$ was activated in our mouse model of SAP. We noted that the rhHMGB1 pancreas-targeted injection activated the TLR4mediated NF- $\kappa \mathrm{B}$ signaling pathway and induced pancreatic injury in wild-type mice. In TLR4-deficient mice, the rhHMGB1induced activation of NF- $\mathrm{KB}$ and pathological changes in the pancreas were less evident than in wild-type mice. Therefore, this study provides evidence that HMGB1 promotes the pathogenesis of pancreatitis, and its downstream TLR4-mediated $\mathrm{NF}-\mathrm{kB}$ signaling pathway is a potential important mediator in the development of this form of pancreatic injury.
\end{abstract}

\section{Introduction}

Severe acute pancreatitis (SAP) is an extremely dangerous acute abdominal disorder which causes multiple complications,

Correspondence to: Dr Hai Yuan or Dr Xing Jin, Department of Vascular Surgery, Shandong Provincial Hospital Affiliated to Shandong University, 324 Jing Wu Wei Qi Road, Jinan, Shandong 250021, P.R. China

E-mail: yuanhai_88888@163.com

E-mail: jinxing_88888@163.com

Key words: severe acute pancreatitis, high-mobility group box 1, Toll-like receptor 4 , nuclear factor- $\kappa \mathrm{B}$, recombinant human highmobility group box 1 and has a high mortality rate $(1,2)$. Despite significant improvements to the methods of diagnosis and management of SAP, the mortality rate has not declined significantly in the past few decades (3). Therefore, the treatment of SAP remains problematic. It is thus critical to investigate the molecular mechanisms responsible for the development of this complex disease, particularly those that activate the innate immune response (4). Some previous studies have suggested that the severity and outcome of pancreatitis may be determined by events that occur after acinar cell injury $(4,5)$.

The high-motility group box protein 1 (HMGB1), with a low molecular weight (approximately $30 \mathrm{kDa}$ ), was originally identified as a non-histone DNA-binding nuclear protein which is involved in both intracellular and extracellular activities (6-10). Extracellular HMGB1 with cytokine-like properties $(7,10)$ is a proximal trigger that induces the release of other cytokines, including tumor necrosis factor- $\alpha$ (TNF- $\alpha$ ), interleukin (IL)-1 $\beta$ and IL-6, which are classically associated with mediating the inflammatory response $(11,12)$. We, as well as others have previously indicated that HMGB1 is elevated in pancreatic tissue during acute pancreatitis, and this elevation is closely linked with the severity of the disease $(1,3,13,14)$. These results suggest that HMGB1 plays a pivotal role in the pathogenesis of SAP. However, the mechanisms underlying this strong correlation remain unclear.

Toll-like receptor (TLR) 4 is one of the least common 11 mammalian pattern-recognition receptors that comprise the innate immune response. It is activated by the prototypical pathogen-associated molecular pattern (PAMP) and damage-associated molecular pattern (DAMP) proteins, such as heat shock protein 70 (HSP70) and HMGB1 $(15,16)$. Extracellular PAMPs or DAMPs that bind to TLR4 cause the myeloid differentiation primary response gene 88 (MyD88) to activate nuclear factor- $\kappa-\mathrm{B}(\mathrm{NF}-\kappa \mathrm{B})$. Activated NF- $\mathrm{KB}$ is transported to the nucleus from the cytoplasm, where it induces the expression of inflammatory factors, including TNF- $\alpha$, IL-1 $\beta$ and IL-6 (17-19). Extracellular HMGB1 functions as a damage-associated molecular pattern molecule, and it activates pro-inflammatory signaling pathways by activating pattern recognition receptors, including TLR $2 / 4$ and the receptor for advanced glycation end-products (RAGE) $(20,21)$. Previous studies have shown that TLR4 plays an important role in the 
pathogenesis of HMGB1-mediated acute lung injury $(6,22)$. Moreover, TLR4 is widely distributed in the tissue and vascular endothelial cells of the pancreas, and has been reported to be associated with pancreatic injury during acute pancreatitis $(4,5,23)$. The triggering of the TLR4 signaling pathway by $\mathrm{HMGB} 1$ activates $\mathrm{NF}-\kappa \mathrm{B}$, which subsequently induces the expression of inflammatory factors $(6,22)$. Excessive cytokine-mediated inflammation plays a fundamental role in the pathogenesis of SAP.

Based upon these findings, we hypothesized that HMGB1 is involved in the pathogenesis of SAP, and that its downstream TLR4-mediated NF- $\kappa \mathrm{B}$ signaling pathway acts as an important mediator in the development of pancreatic injury. In this study, a murine model of acute pancreatitis, induced by the intraperitoneal injection of L-arginine, was used. To examine the role of TLR4 in the pathogenesis of HMGB1-induced pancreatic injury, TLR4-deficient mice were used.

\section{Materials and methods}

Experimental animals. Male C57BL/6 mice (Shandong University Experimental Animal Center, Jinan, China) and male C57BL/10ScNJ TLR4 ${ }^{-/}$mice (Jackson Laboratories, Bar Harbor, ME, USA) were used in this study. The mice were housed and bred in micro-isolators under specific pathogenfree conditions, in a climate-controlled enrivonment with an ambient temperature of $22^{\circ} \mathrm{C}$ and a $12: 12 \mathrm{~h}$ light/dark cycle. They were fed standard laboratory chow, and drinking water was available ad libitum. All experiments were performed using wild-type (WT) and deficient mice that were 6-8 weeks old and weighed 20-30 g. All experimental protocols were approved by the Ethics Review Board of Shandong University. All animals received care in accordance with the guidelines for animal care published by the United States National Institutes of Health (NIH) for animal care (Guide for the Care and Use of Laboratory Animals, Department of Health and Human Services, NIH Publication no. 86-23, revised 1985).

\section{Animal model and experimental groups}

Induction of pancreatitis. The model of L-arginine-induced SAP was created as previously described (24). Male C57BL/6 mice were used and were randomly divided into the following 2 groups: i) the sham injection group (sham): animals in this group received 2 sham intraperitoneal injections of sterile saline alone, with a 1-h interval between injections; and ii) the SAP group: animals in this group received 2 intraperitoneal injections of $8 \% \mathrm{~L}$-arginine, which were both at concentrations of $400 \mathrm{mg} / 100 \mathrm{~g}$ body weight, with a 1-h interval between injections. Under intraperitoneal anesthesia with $10 \%$ chloral hydrate, the mice were sacrificed by exsanguination $48 \mathrm{~h}$ after the second injection $(\mathrm{n}=6)$.

rhHMGB1 stimulation model. To create the model of rhHMGB1-induced pancreatic injury, C57BL/6 $\left(\mathrm{TLR}^{+/+}\right)$mice were randomly divided into the following 3 groups ( $n=6 /$ group) and were administered a pancreas-targeted injection. The mice were divided into the following 3 groups: i) the sham injection group (sham): animals in this group received a pancreas-targeted ultrasound-guided injection of $0.25 \mathrm{ml}$ sterile saline alone; ii) the low-dose group (HM-LD): animals in this group received a pancreas-targeted ultrasound-guided injection of rhHMGB1
(SinoBio, Shanghai, China; $50 \mu \mathrm{g} / \mathrm{kg}$ body weight), diluted in $0.25 \mathrm{ml}$ sterile saline; and iii) the high-dose group (HM-HD): animals in this group received a pancreas-targeted ultrasound-guided injection of rhHMGB1 $(100 \mu \mathrm{g} / \mathrm{kg}$ body weight), diluted in $0.25 \mathrm{ml}$ sterile saline. Under intraperitoneal anesthesia with $10 \%$ chloral hydrate, the animals were sacrificed by exsanguination $48 \mathrm{~h}$ after treatment.

TLR4-deficient model. The C57BL/6 (WT) and C57BL/10ScNJ (TLR4-deficient; TLR4 ${ }^{-/}$) mice were independently and randomly divided into the WT and TLR4-deficient groups ( $\mathrm{n}=6 /$ group): i) the WT group: the C57BL/6 mice in this group received a pancreas-targeted ultrasound-guided injection of rhHMGB1 (100 $\mu \mathrm{g} / \mathrm{kg}$ body weight), diluted in $0.25 \mathrm{ml}$ sterile saline; ii) the TLR4-deficient group (TLR4 ${ }^{-/}$): $\mathrm{C} 57 \mathrm{BL} / 10 \mathrm{ScNJ}$ mice in this group received the same treatment as the mice in the WT group. Under intraperitoneal anesthesia with $10 \%$ chloral hydrate, the animals were sacrificed by exsanguination $48 \mathrm{~h}$ post-treatment.

Sample collection. The animals were anesthetized with an intraperitoneal injection of pentobarbital sodium $(100 \mathrm{mg} / \mathrm{kg})$. The serum and pancreas were stored at $-80^{\circ} \mathrm{C}$ until further use. Tissues for histopathological analysis were fixed in $10 \%$ buffered formaldehyde solution overnight. The tissue was then embedded the following day.

Histopathological analysis. For assessing the changes occurring in the pancreatic tissue at the morphological level, $5-\mu$ m-thick sections of pancreatic tissue were stained with hematoxylin and eosin $(\mathrm{H} \& \mathrm{E})$. The severity of SAP in the pancreatic tissue was measured using the improved methods of Schmidt et al (25) and Pozsar et al (26) with i) edema: 0 , null; 1 , interlobar space broadened gently; 2 , interlobar space broadened severely; 3 , interacinous space broadened; 4 , intercellular space broadened; ii) necrosis: 0 , null; $1,1-10 \%$ necrotic area; $2,11-20 \%$ necrotic area; $3,21-30 \%$ necrotic area; and $4,>30 \%$ necrotic area; iii) hemorrhage: 0 , negative; and 1, positive; and iv) inflammatory cell infiltration: the number of leucocytes in the lobule and around blood vessels was counted in a high-power field with $0,0-1 ; 1,2-10 ; 2,11-20 ; 3,21-30$; and $4,>30$ or micro-abscesses. Moreover, a total pancreatic injury score was calculated as the sum of the 4 components. Five fields of each section were counted, and the average score of these 5 fields was the pathological injury score of this section.

Western blot analysis. The levels of pancreatic HMGB1, TLR4 and NF- $\mathrm{B}$ p 65 were measured by western blot analysis. The pancreas was harvested, washed 3 times in sterile saline and then homogenized in RIPA buffer (Beyotime Institute of Biotechnology, Suzhou, China) containing a protease inhibitor cocktail (Thermo Scientific, Rockford, IL, USA). Nucleus extraction from the pancreatic tissue was prepared using the Pierce Nucleus and Cytoplasmic Extraction Reagent kit (Thermo Scientific) containing a protease inhibitor cocktail and phosphatase inhibitor cocktail (Roche, Basel, Germany) according to the manufacturers' instructions. Following centrifugatoin at $16,000 \mathrm{x} \mathrm{g}$ at $4^{\circ} \mathrm{C}$ for $30 \mathrm{~min}$, the supernatant was collected.

Protein was quantified using a BCA Protein Assay kit (Beyotime Institute of Biotechnology). Samples of $40 \mu \mathrm{g}$ were 
run on $8 \%$ SDS-PAGE (TLR4) and 10\% SDS-PAGE (HMGB1 and NF- $\kappa$ B p65) gels. Proteins were then electrotransferred onto polyvinylidene difluoride (PVDF) membranes (Beyotime Institute of Biotechnology). The membranes were incubated in TBST containing $5 \%$ non-fat dried milk for $1 \mathrm{~h}$ at $25^{\circ} \mathrm{C}$. The blots were then incubated overnight at $4^{\circ} \mathrm{C}$ with primary antibodies to HMGB1 (ab79823), TLR4 (ab22048), p65 (ab16502; all from Abcam, Boston, MA, USA), $\beta$-actin (sc-47778; ZSGB-BIO, Beijing, China) or histone H3 (ab76307; Abcam). Subsequently, they were incubated with the appropriate horseradish peroxidase (HRP)-conjugated anti-rabbit (ZB-2301) or anti-mouse (ZB-2305) secondary antibodies (ZSGB-BIO) for $1 \mathrm{~h}$ at $25^{\circ} \mathrm{C}$ and visualized with an enhanced chemiluminescence assay (Thermo Scientific). The bands were quantified using MultiGauge version 3.2 software. Experiments were repeated independently 3 times, and the relative expression of the target protein was normalized to the level of $\beta$-actin or histone $\mathrm{H} 3$ in the same sample.

Enzyme-linked immunosorbent assay (ELISA). The levels of serum amylase and lipase were detected by the laboratory of Shandong Provincial Hospital affiliated to Shandong University. The serum levels of HMGB1 were detected using commercial ELISA kits (Shino-Test Corp., Tokyo, Japan) according to the manufacturer's instructions. Blood samples were collected from the eye veins of the mice after they were anesthetized, and the samples were centrifuged at 3,000 $\mathrm{x}$ g for $10 \mathrm{~min}$ at $4^{\circ} \mathrm{C}$ to collect the serum. The serum was kept at $-80^{\circ} \mathrm{C}$ until analysis.

The TNF- $\alpha$ and IL-1 $\beta$ levels in the pancreatic tissue were detected using commercial ELISA kits (ExCell Bio, Shanghai, China) according to the instructions provided by the manufacturer. Protein extraction and concentration determination were performed using the same procedures as described for western blot analysis.

Reverse transcription-quantitative PCR (RT-qPCR). Total RNA was extracted from the pancreatic tissue using TRIzol reagent (Takara, Tokyo, Japan). Using $1 \mu \mathrm{g}$ total RNA, firststrand cDNA was synthesized by the AMV enzyme in $20 \mu \mathrm{l}$ reaction mixture (Takara). Using $2 \mu 1$ reverse transcriptase products, quantitative PCR was performed in a final volume of $20 \mu 1$ using gene-specific primers. The following primers designed by Takara were used: mouse TLR4, 5'-CATGGATCA GAAACTCAGCAAAGTC-3' (sense), and 5'-CATGCCAT GCCTTGTCTTCA-3' (antisense); mouse HMGB1, 5'-TTTA GATAGCCCTGTCCTGGTGGTA-3' (sense), and 5'-GTGCA CCAACAAGAACCTGCTTTA-3' (antisense); and mouse actin, 5'-CATCCGTAAAGACCTCTATGCCAAC-3' (sense), and 5'-ATGGAGCCACCGATCCACA-3' (antisense). Amplification was carried out as follows: $95^{\circ} \mathrm{C}, 30 \mathrm{sec}, 1$ cycle; $95^{\circ} \mathrm{C}$, $3 \mathrm{sec}$ and $60^{\circ} \mathrm{C} 30 \mathrm{sec}$ for 40 cycles; subsequently, the melting curve was determined. Gene transcripts were quantified with SYBR Premix Ex Taq kit (Takara). Data were calculated using the $2^{-\Delta \Delta \mathrm{CT}}$ method and presented as the fold change of transcripts for the HMGB1 and TLR4 genes in the pancreatic tissue of the other groups compared with the control group (defined as 1.0-fold). Mouse actin was used as a constitutive control. The relative expression of the target gene was normalized to the level of actin in the same cDNA.
Statistical analysis. All values are expressed as the means \pm SD. Analysis of variance (ANOVA) followed by Tukey's multiple comparison tests were used. A P-value $<0.05$ was considered to indicate a statistically significant difference.

\section{Results}

Mouse model of SAP induced by L-arginine. The murine model of acute pancreatitis induced by L-arginine is a widely accepted model (4,24,27-29). In the present study, $48 \mathrm{~h}$ following treatment with $8 \%$ L-arginine, SAP was observed, according to the morphological characteristics and serum amylase and lipase levels. In the SAP group, the pancreatic tissue exhibited marked edema and was infiltrated by inflammatory cells; a mass of necrotic acinar cells and the disappearance of normal structure in the pancreatic lobes were also observed in the mice in this group (Fig. 1A, panel b). As shown in Fig. 1C, in the mice in the SAP group, but not those which received the sham injection, a marked increase in the serum amylase and lipase levels was noted.

Elevated HMGB1 and TLR4 expression in mice with SAP. Compared with the animals treated with the sham injection, the mice with SAP exhibited increased HMGB1 mRNA and protein levels in pancreatic tissue (Fig. 2A). The mice with SAP also exhibited increased serum HMGB1 levels (Fig. 2A, panel a), which indicated that HMGB1 was likely secreted into the extracellular space. Compared with the mice which received the sham injection, increased TLR4 mRNA and protein levels were observed in the mice with SAP (Fig. 2B).

$N F-\kappa B$ is activated during SAP. As shown in Fig. 2C, compared with the mice treated with the sham injection, the protein levels of nuclear $\mathrm{p} 65$ in the pancreatic tissue from the mice in the SAP group were significantly increased. The results from ELISA revealed that the TNF- $\alpha$ and IL- $1 \beta$ levels in the pancreatic tissue of the mice in the SAP group were higher than those in the tissue of the mice in the sham injection group (Fig. 2C).

rhHMGB1 induces pancreatic injury in mice. WT mice $(\mathrm{C} 57 \mathrm{BL} / 6)$ were administered a pancreas-targeted ultrasound-guided injection of rhHMGB1 to determine whether it contributes to pancreatic injury. Histological analysis of the pancreas was performed $48 \mathrm{~h}$ following treatment. As shown in Fig. 3A, the pancreatic tissue from the mice in the sham injection group had a normal structure. By contrast, the pancreatic tissue from the mice in the rhHMGB1 groups exhibited characteristics of pancreatic injury, including considerable edema, neutrophil infiltration and acinar cell necrosis. More intense accumulation of neutrophils and a mass of necrotic acinar cells were also observed in the high-dose group, indicating a change in the histology in response to various doses of rhHMGB1. The serum amylase and lipase levels were also increased in a dose-dependent manner in the rhHMGB1 groups compared to the sham injection group.

rhHMGB1 increases TLR4 expression and activates $N F-\kappa B$. Following the administration of rhHMGB1, the TLR4 mRNA expression level in the pancreatic tissue was significantly increased in the rhHMGB1 groups compared to sham injec- 
A a

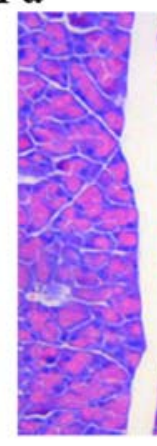

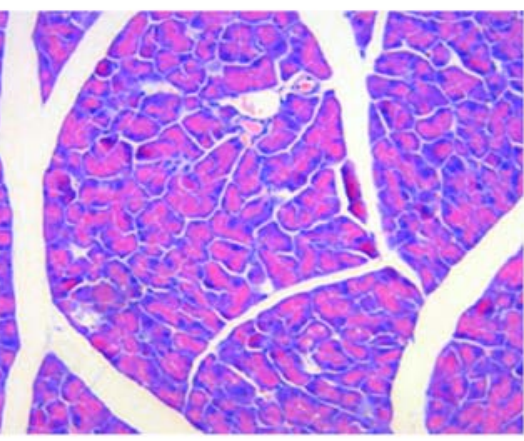

b

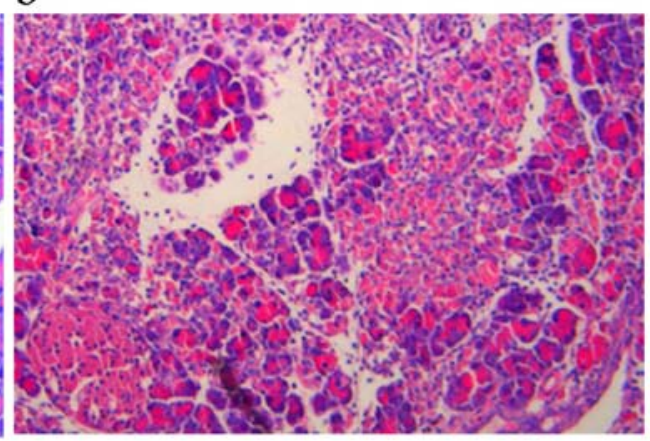

B

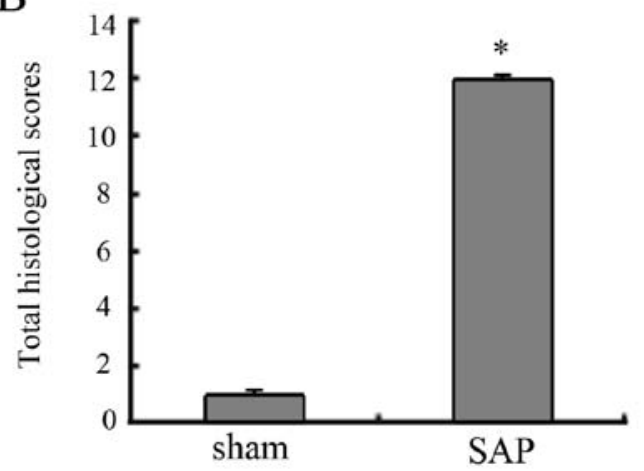

$\mathrm{C}$

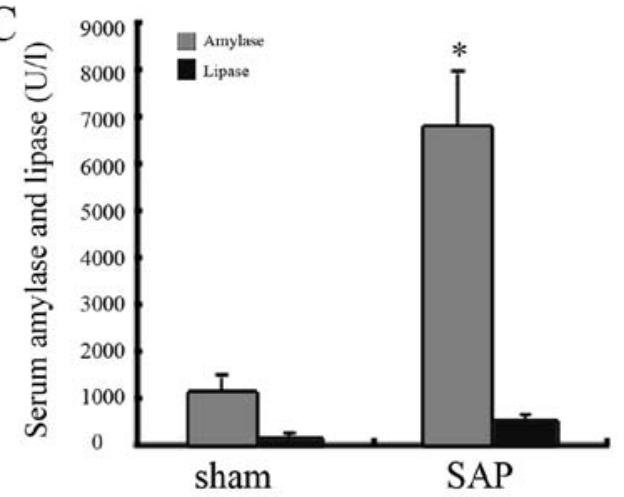

Figure 1. Model of severe acute pancreatitis (SAP). (A) Histopathological changes of the pancreas: representative H\&E-stained micrographs (original magnification, x200) from the (a) sham and (b) SAP groups are presented. The pancreatic tissues in the SAP group exhibited marked edema and infiltration of inflammatory cells; a mass of necrotic acinar cells and the disappearance of normal structure in pancreas lobes were also observed. (B) Histological scores of the pancreas in the sham and SAP groups. (C) Changes in serum amylase and lipase levels in sham and SAP groups. Data are expressed as the means \pm SD ( $\mathrm{n}=6$ /group). ${ }^{*} \mathrm{P}<0.01$ compared to the sham injection group (control group). Sham, sham injection.

tion group. Similar results were also observed in relation to the protein expression levels (Fig. 4A).

Following the administration of rhHMGB1, as shown in Fig. 4B, NF- $\mathrm{KB}$ was activated in the rhHMGB1 groups, as observed from the increase in nuclear p65 expression and its downstream TNF- $\alpha$ and IL-1 $\beta$ expression. Additionally, in relation to rhHMGB1 stimulation, TLR4 expression and NF- $\mathrm{BB}$ activation was noted to be dependant on the concentration of rhHMGB1.

TLR4 mediates rhHMGB1-induced pancreatic injury. The assessment was performed at $48 \mathrm{~h}$ following the high-dose administration of rhHMGB1. The pancreatic tissue from the mice in the WT group exhibited characteristics of pancreatic injury, including considerable edema, infiltration of inflammatory cells, a mass of necrotic acinar cells and the disappearance of the normal pancreatic lobe structure (Fig. 5A). However, in the TLR4-deficient group, there was a significant reduction in pancreatic injury (Fig. 5A, panel b). The serum amylase and lipase levels of mice in the deficient group were also significantly reduced compared to the mice in the WT group (Fig. 5B, panel b).

As shown in Fig. 5C, NF- $\mathrm{B}$ in the TLR4-deficient group was moderately activated compared with the intense activation in the WT groups following the administration of rhHMGB1. These results are clear from nuclear p65 expression and its downstream concentrations of TNF- $\alpha$ and IL- $1 \beta$ in both groups of mice.

\section{Discussion}

SAP is an acute necrotic inflammation process that suddenly occurs in the peripheral and internal areas of the pancreas. At present, the pathogenesis of SAP remains incompletely understood, leading to a lack of proper strategies for treating SAP. However, the previously proposed inflammatory mediator theory provides new information for SAP research (2). The increase in the levels of inflammatory cytokines is closely associated with the severity of SAP, and these inflammatory cytokines cause systemic inflammatory response syndrome SIRS), multiple organ dysfunction syndrome (MODS) and death.

We, as well as others have previously demonstrated that HMGB1 is involved in the systematic inflammatory response of SAP, that it appeares in the late phase and has a long duration $(1,3,13)$; however, the underlying mechanisms have not yet been fully elucidated. Yang et al (6) and Deng et al (22) found that TLR4 mediated HMGB1-induced acute lung injury. However, to the best of our knowledge, no studies to date have demonstrated the potential role of TLR4 in HMGB1-induced pancreatic injury.

The aim of this study was to further investigate whether HMGB1 is involved as a stimulating factor, and whether its downstream TLR4-mediated NF- $\mathrm{NB}$ signaling pathway mediates the development of experimental pancreatic injury, with the aim of developing further treatments for SAP. In this study, C57BL/6 mice exposed to L-arginine had detectable SAP, as 
A a

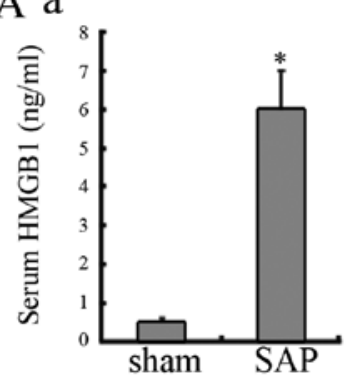

$\mathrm{B}$

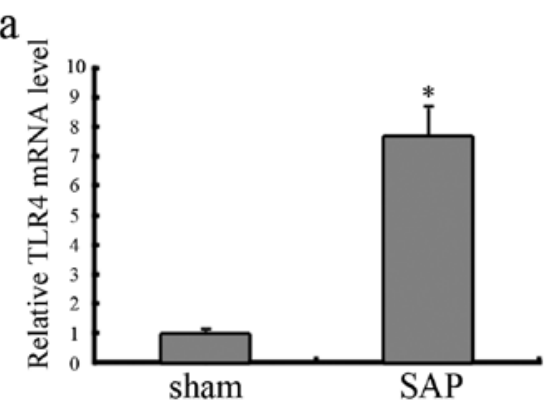

C

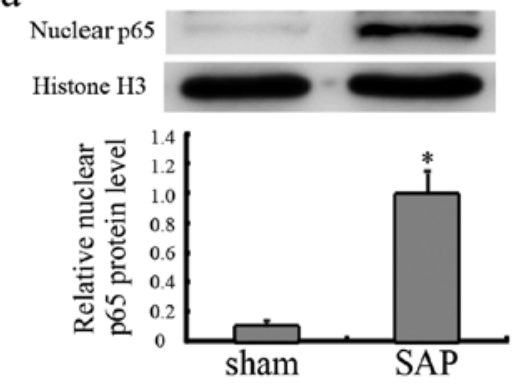

b

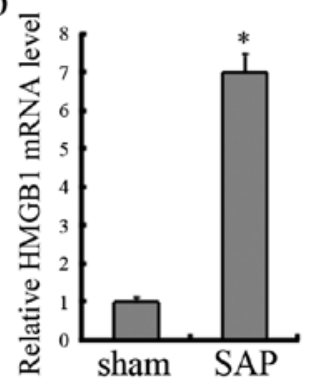

$\mathrm{b}$

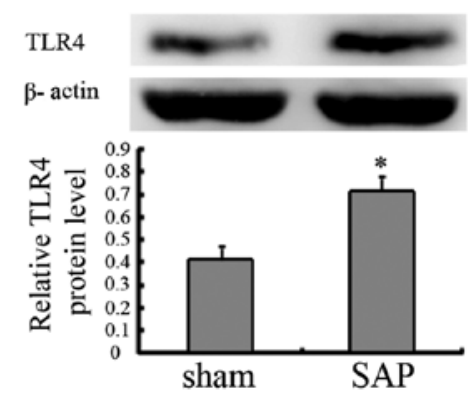

$\mathrm{b}$

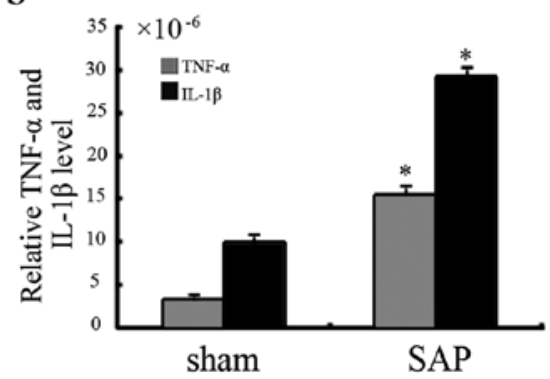

Figure 2. Expression of high-mobility group box 1 (HMGB1) and Toll-like receptor 4 (TLR4) and activation of nuclear factor- $\kappa \mathrm{B}$ (NF- $\kappa \mathrm{B})$ in pancreatic tissue from mice after L-arginine administration or sham injection. (A) Serum HMGB1 concentrations [(a) ELISA] were assessed in the sham and severe acute pancreatitis (SAP) groups. The expression of HMGB1 was assessed using the mRNA [(b) qPCR] and protein [(c) western blot analysis] levels in the pancreas tissue from the sham and SAP groups. (B) The expression of TLR4 was assessed with the mRNA [(a) qPCR] and protein [(b) western blot analysis] levels in the pancreatic tissue from the sham and SAP groups. (C) The activation of NF- $\mathrm{B}$ was assessed from the nuclear p65 [(a) western blot analysis] and its downstream, relative levels of

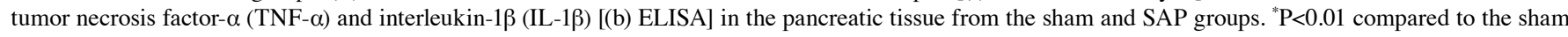
group (control group). The relative levels of HMGB1 and TLR4 protein and mRNA compared to the control group are normalized to $\beta$-actin. The relative levels of nuclear p65 protein compared to the control group are normalized to histone H3. The relative levels of TNF- $\alpha$ and IL-1 $\beta$ compared to the control group are normalized to the total protein concentration of each sample. Data are expressed as the means $\pm \mathrm{SD}$ ( $\mathrm{n}=6 / \mathrm{group}$ ). Blots shown are from a representative experiment that was repeated 3 times with similar results ( $n=6 /$ group). Sham, sham injection.

observed at the pathological level and through serum amylase and lipase levels, which is consistent with previous reports on L-arginine-induced SAP (4,24,27-29). Moreover, significantly elevated levels of HMGB1, TLR4 and NF- $\kappa \mathrm{B}$ activation in the pancreatic tissue were observed in the mice with SAP. These results from our study are in agreement with previous observations $(3,12-14,23)$. Therefore, we suggest that the HMGB1 and the TLR4-mediated NF- $\kappa \mathrm{B}$ signaling pathway play a cooperative role in the development of pancreatic injury during acute pancreatitis.

HMGB1, which was originally identified as a DNA-binding protein, exhibits pro-inflammatory cytokine-like properties when it is excreted into the extracellular space. In previous studies, HMGB1 was found to be a regulator and inducer that is involved in a number of diseases, such as sepsis, ischemia-reperfusion injury, rheumatoid arthritis, thromboangiitis obliterans, abdominal aortic aneurysm and acute pancreatitis $(12,14,30-35)$. In addition, anti-HMGB1-based therapy using HMGB1 inhibitors, such as neutralizing antiHMGB1 antibody, A box and the anti-inflammatory agents, ethyl pyravate and sodium butyrate, has been shown to have beneficial effects on HMGB1-related diseases (12,14,30-35). In the present study, we noted that in mice with SAP, serum HMGB1 levels significantly increased, indicating that HMGB1 was secreted into the extracellular space. To determine whether HMGB1 alone induced pancreatic injury in mice, we used a pancreas-targeted ultrasound-guided injection of various doses of rhHMGB1 in mice and then observed pancreatic histology $48 \mathrm{~h}$ after administration. We observed considerable edema, infiltration of inflammatory cells, a mass of necrotic acinar 


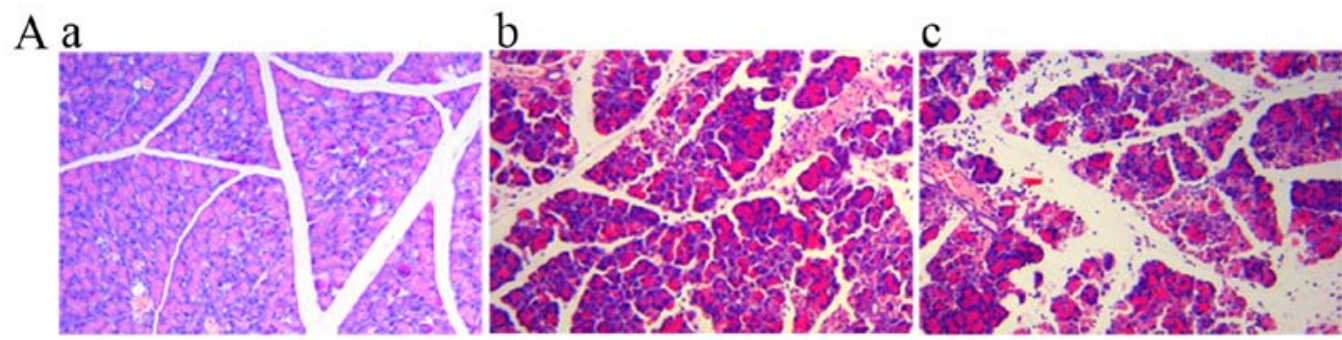

B

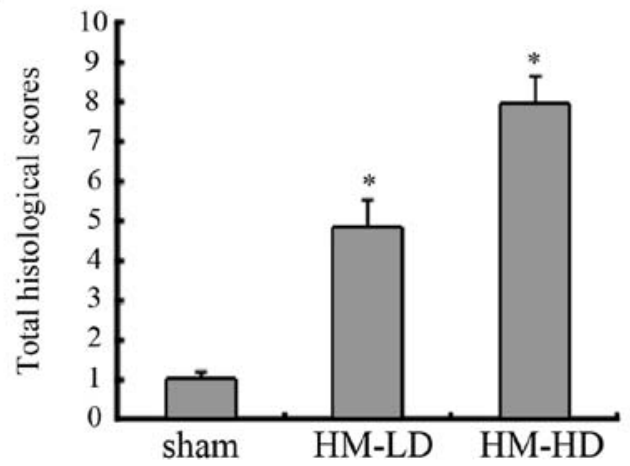

C

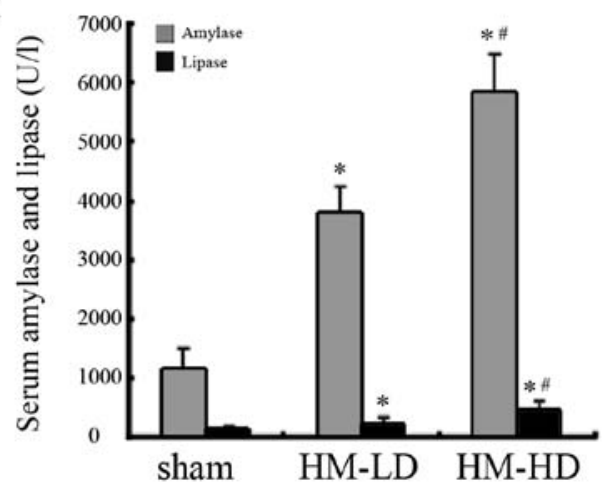

Figure 3. Pancreatic injury induced by recombinant human high-mobility group box 1 (rhHMGB1). (A) Histopathological changes of the pancreas in response to rhHMGB1 administration in mice at $48 \mathrm{~h}$. Representative H\&E-stained micrographs (original magnification, x200) from the (a) sham, (b) low dose of HMGB1 (HM-LD) and (c) high dose of HMGB1 (HM-HD) groups. The pancreatic tissues in the HM-LD group exhibited marked edema, neutrophil infiltration and acinar cell necrosis; more intense accumulation of neutrophils and a mass of necrotic acinar cells were also observed in the HM-HD group. (B) Histological scores of the pancreas in the sham, HM-LD and HM-HD groups. (C) Serum amylase and lipase changes in the sham, HM-LD and HM-HD groups. Data are expressed as the means $\pm \mathrm{SD}$ (n=6/group). ${ }^{*} \mathrm{P}<0.01$ compared to the sham group (control group); ${ }^{\prime \prime} \mathrm{P}<0.05$ compared to the HM-LD group. Sham, sham injection.

A a

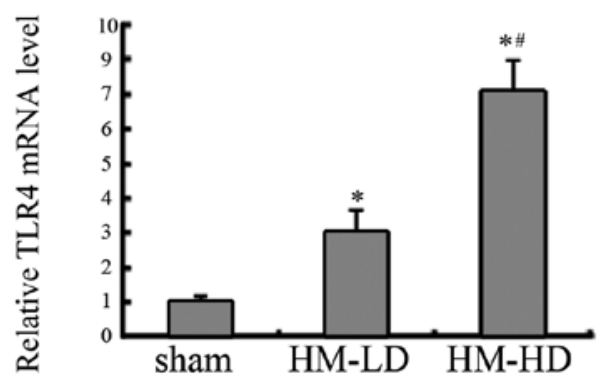

B a

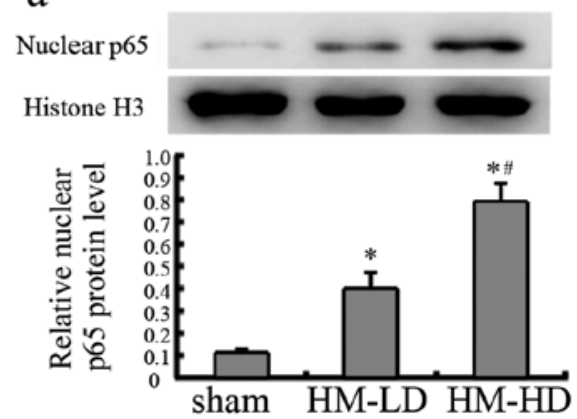

b

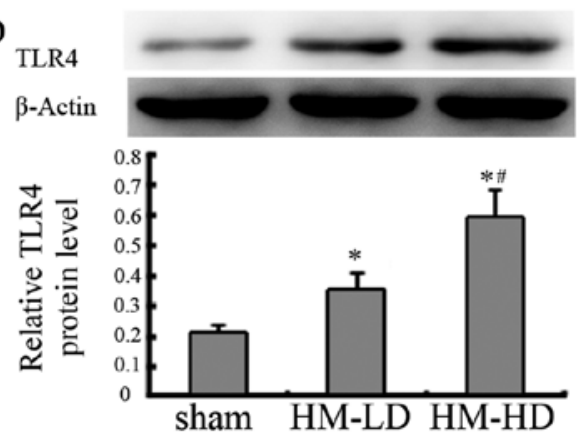

$\mathrm{b}$

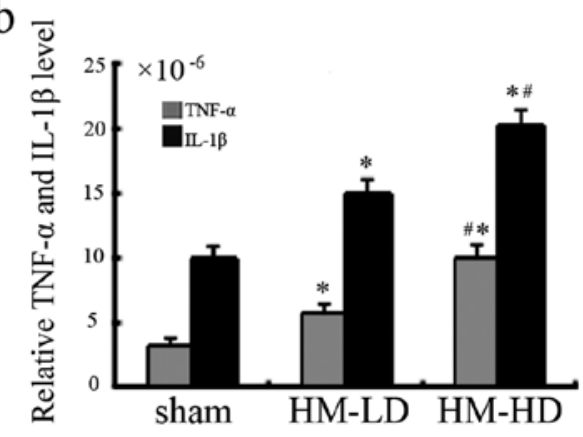

Figure 4. Toll-like receptor 4 (TLR4) expression and nuclear factor- $\mathrm{\kappa B}(\mathrm{NF}-\mathrm{\kappa B})$ activation in pancreatic tissue after recombinant human high-mobility group box 1 (rhHMGB1) administration. (A) The expression of TLR4 was assessed using the mRNA [(a) qPCR] and protein [(b) western blot analysis] levels in the pancreatic tissue from the sham, low-dose of HMGB1 (HM-LD) and high-dose of HMGB1 (HM-HD) groups at $48 \mathrm{~h}$ after rhHMGB1 administration. (B) The activation of NF- $\mathrm{kB}$ was assessed from the nuclear p65 [(a) western blot analysis] and its downstream, relative levels of tumor necrosis factor- $\alpha$ (TNF- $\alpha$ ) and interleukin-1 $\beta$ (IL-1 $\beta$ ) [(b) ELISA] in the pancreatic tissue of the sham, HM-LD and HM-HD groups. ${ }^{*} \mathrm{P}<0.01$ compared to the sham group (control group); ${ }^{*} \mathrm{P}<0.05$ compared to the HM-LD group. The relative levels of the TLR4 protein and mRNA compared to the control group are normalized to $\beta$-actin. The relative levels of nuclear p65 protein compared to the control group are normalized to histone H3. The relative levels of TNF- $\alpha$ and IL-1 $\beta$ concentrations compared to the control group are normalized to the total protein concentration of each sample. Data are expressed as the means $\pm \mathrm{SD}$ ( $\mathrm{n}=6 /$ group). Blots shown are from a representative experiment that was repeated 3 times with similar results (n=6/group). Sham, sham injection. 
A a

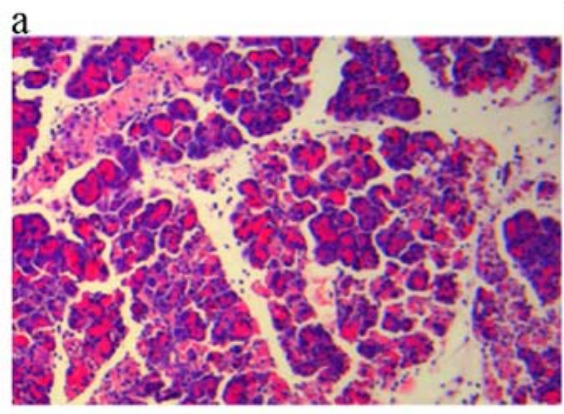

b

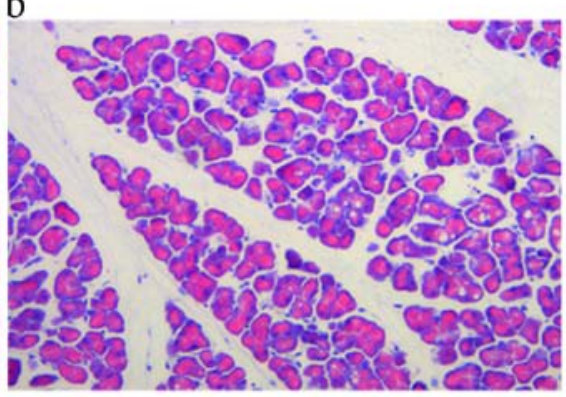

B a

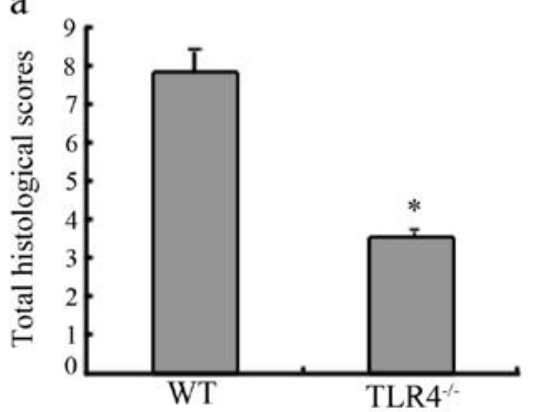

b

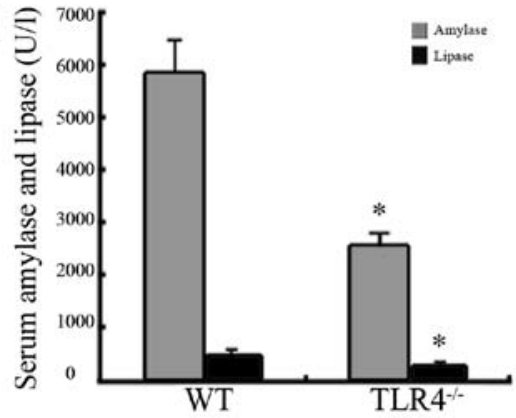

$\mathrm{Ca}$

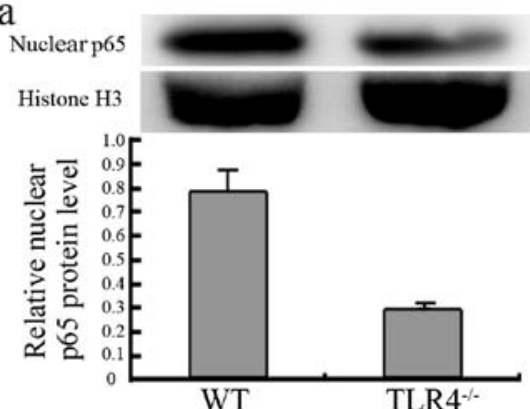

b

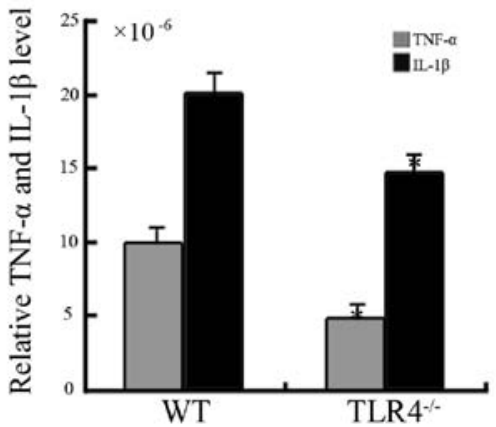

Figure 5. Response of Toll-like receptor 4 (TLR4)-deficient mice to recombinant human high-mobility group box 1 (rhHMGB1) administration. (A) Pancreatic histopathological changes in wild-type (WT) and TLR4-deficient mice $48 \mathrm{~h}$ after the administration of a high dose of rhHMGB1. Representative H\&E-stained micrographs (original magnification, x200) from the (a) WT and (b) TLR 4 - groups. The pancreatic tissues in the wild-type group exhibited marked edema, infiltration of inflammatory cells, a mass of necrotic acinar cells and the disappearance of the normal lobe structure in the pancreas; there was a significant reduction in the TLR4-deficient group. (B-a) Histological scores of the pancreas and (b) serum amylase and lipase changes in the WT and TLR4 ${ }^{-/}$groups. (C) The activation of nuclear factor- $\mathrm{kB}$ (NF-kB) was assessed from the nuclear p65 [(a) western blot analysis] and its downstream, relative levels of tumor necrosis factor- $\alpha$ (TNF- $\alpha$ ) and interleukin-1 $\beta$ (IL-1 $\beta$ ) [(b) ELISA] in the pancreatic tissue from the WT and TLR4 ${ }^{-1}$ groups. ${ }^{*} \mathrm{P}<0.01$ compared to the WT group. The relative levels of nuclear p65 protein compared to the control group are normalized to histone 3 (H3). The relative levels of TNF- $\alpha$ and IL-1 $\beta$ compared to the control group are normalized to the total protein concentration of each sample. Data are expressed as the means $\pm \mathrm{SD}(\mathrm{n}=6 /$ group). Blots shown are from a representative experiment that was repeated 3 times with similar results (n=6/group). WT, WT mice given a high dose of rhHMGB1; TLR4 ${ }^{--}$, TLR4-deficient mice administered a high dose of rhHMGB1.

cells, disappearance of the normal pancreas lobe structure and significantly elevated serum amylase and lipase levels in the mice in the rhHMGB1 groups, accounting for pancreatic injury. These results are similar to previous observations made in relation to mice and rats, which showed that acute lung inflammatory injury was prompted by the intratracheal instillation of HMGB1 $(12,22,36)$. In the present study, we also found that the severity of pancreatic injury was dose dependent. These results suggest that extracellular HMGB1 alone induces pancreatic injury in a dose-dependent manner. Recently, Kang et al (37) found that intracellular HMGB1 inhibited inflammatory nucleosome release and exerted a protective function in cases of acute pancreatitis. This was due to the fact that nuclear HMGB1 directly interacted with the nucleosome to maintain chromosomal structure, function and stability and regulate DNA damage responses (38-43). Kang et al (37) also found that extracellular HMGB1 acted as a pro-inflammatory cytokine in cases of acute pancreatitis, which was consistent with our finding.

TLR4 plays an important role in the innate immune response. It is both an immune recognition receptor on the cell surface and a transmembrane signal transduction molecule. When TLR4 is activated by PAMPs or DAMPs, it activates the MyD88- and TRIF-dependent pathways, activating intracellular signaling molecules, such as the interleukin-1 receptor-associated kinases (IRAKs), tumor necrosis factor receptor-associated factors (TRAFs) and TAK1. Therefore, it ultimately forms the primary and secondary signal waves that activate $\mathrm{NF}-\kappa \mathrm{B}$, which induces the transcription and translation of inflammatory cytokines and leads to the massive release of inflammatory mediators $(17-19,44)$. In this study, using a murine model of pancreatitis, the expression of TLR4 and NF- $\mathrm{kB}$ activation were elevated in pancreatic 
tissue, and these results suggest that the TLR4-mediated NF- $\mathrm{BB}$ signaling pathway plays a role in this form of pancreatic injury. HMGB1 activates inflammatory pathways by stimulating TLR4 in many types of tissue injury $(6,22,45,46)$. However, it remains to be determined whether the TLR4-mediated NF- $\mathrm{BB}$ signaling pathway mediates HMGB1-induced pancreatic injury. To evaluate this form of pancreatic injury, we administered pancreas-targeted rhHMGB1 to WT and TLR4-deficient mice and then harvested pancreatic tissues $48 \mathrm{~h}$ after treatment. In the WT group, we noted that rhHMGB1 upregulated TLR4 expression, activated $\mathrm{NF}-\kappa \mathrm{B}$ and induced pancreatic injury. These results suggest that rhHMGB1 alone upregulates TLR4 expression and activates the TLR4-mediated NF- $\kappa \mathrm{B}$ signaling pathway to induce pancreatic injury. However, in TLR4-deficient mice, the extent of pancreatic injury was significantly reduced, and the activation of NF- $\kappa \mathrm{B}$ was lower than that in the WT mice. In spite of the modest effect on pancreatic injury in TLR4-deficient mice after the rhHMGB1 injection, we found that HMGB1-induced pancreatic injury is predominantly mediated by the TLR4mediated $\mathrm{NF}-\mathrm{\kappa B}$ signaling pathway.

In conclusion, our results suggest that HMGB1 is involved in the development of SAP. These findings contribute to a better understanding of the mechanisms underlying the pathogenesis of SAP. Manipulation of the interaction between HMGB1 and TLR4 will likely ultimately lead to the development of novel therapies for treating and preventing the progression of SAP.

\section{Acknowledgements}

This study was supported by the National Science Fund for Distinguished Young Scholars (no. 81000186).

\section{References}

1. Yuan H, Jin X, Sun J, Li F, Feng Q, Zhang C, Cao Y, Wang Y: Protective effect of HMGB1 a box on organ injury of acute pancreatitis in mice. Pancreas 38: 143-148, 2009.

2. Felderbauer P, Müller C, Bulut K, Belyaev O, Schmitz F, Uhl W and Schmidt WE: Pathophysiology and treatment of acute pancreatitis: new therapeutic targets - a ray of hope? Basic Clin Pharmacol Toxicol 97: 342-350, 2005.

3. Zhang ZW, Zhang QY, Zhou MT, Liu NX, Chen TK, Zhu YF and Wu L: Antioxidant inhibits HMGB1 expression and reduces pancreas injury in rats with severe acute pancreatitis. Dig Dis Sci 55: 2529-2536, 2010.

4. Sharif R, Dawra R, Wasiluk K, Phillips P, Dudeja V, Kurt-Jones E, Finberg R and Saluja A: Impact of toll-like receptor 4 on the severity of acute pancreatitis and pancreatitis-associated lung injury in mice. Gut 58: 813-819, 2009.

5. Ding SQ, Li Y, Zhou ZG, Wang C, Zhan L and Zhou B: Toll-like receptor 4-mediated apoptosis of pancreatic cells in cerulein-induced acute pancreatitis in mice. Hepatobiliary Pancreat Dis Int 9: 645-650, 2010.

6. Yang Z, Deng Y, Su D, Tian J, Gao Y, He Z and Wang X: TLR4 as receptor for HMGB1-mediated acute lung injury after liver ischemia/reperfusion injury. Lab Invest 93: 792-800, 2013.

7. Li J, Wang H, Mason JM, Levine J, Yu M, Ulloa L, Czura CJ, Tracey KJ and Yang H: Recombinant HMGB1 with cytokine-stimulating activity. J Immunol Methods 289: 211-223, 2004.

8. Andersson U, Erlandsson-Harris H, Yang $\mathrm{H}$ and Tracey KJ: HMGB1 as a DNA-binding cytokine. J Leukoc Biol 72: 1084-1091, 2002.

9. Dumitriu IE, Baruah P, Manfredi AA, Bianchi ME and RovereQuerini P: HMGB1: guiding immunity from within. Trends Immunol 26: 381-387, 2005.

10. Yang H, Wang H, Czura CJ and Tracey KJ: HMGB1 as a cytokine and therapeutic target. J Endotoxin Res 8: 469-472, 2002.
11. Lotze MT, Zeh HJ, Rubartelli A, Sparvero LJ, Amoscato AA, Washburn NR, Devera ME, Liang X, Tör M and Billiar T: The grateful dead: damage-associated molecular pattern molecules and reduction/oxidation regulate immunity. Immunol Rev 220: 60-81, 2007.

12. Kim JY, Park JS, Strassheim D, Douglas I, Diaz del Valle F, Asehnoune K, Mitra S, Kwak SH, Yamada S, Maruyama I, et al: HMGB1 contributes to the development of acute lung injury after hemorrhage. Am J Physiol Lung Cell Mol Physiol 288: L958-L965, 2005.

13. Sawa H, Ueda T, Takeyama Y, Yasuda T, Shinzeki M, Nakajima T and Kuroda Y: Blockade of high mobility group box-1 protein attenuates experimental severe acute pancreatitis. World J Gastroenterol 12: 7666-7670, 2006.

14. Luan ZG, Zhang XJ, Yin XH, Ma XC, Zhang H, Zhang C and Guo RX: Downregulation of HMGB1 protects against the development of acute lung injury after severe acute pancreatitis. Immunobiology 218: 1261-1270, 2013.

15. Bianchi ME: DAMPs, PAMPs and alarmins: all we need to know about danger. J Leukoc Biol 81: 1-5, 2007.

16. Kawai T and Akira S: The role of pattern-recognition receptors in innate immunity: update on Toll-like receptors. Nat Immunol 11: 373-384, 2010.

17. Noreen M, Shah MA, Mall SM, Choudhary S, Hussain T, Ahmed I, Jalil SF and Raza MI: TLR4 polymorphisms and disease susceptibility. Inflamm Res 61: 177-188, 2012.

18. Wullaert A: Role of NF-kappaB activation in intestinal immune homeostasis. Int J Med Microbiol 300: 49-56, 2010.

19. Luo H, Guo P and Zhou Q: Role of TLR4/NF- $\kappa B$ in damage to intestinal mucosa barrier function and bacterial translocation in rats exposed to hypoxia. PLoS One 7: e46291, 2012.

20. Hori O, Brett J, Slattery T, Cao R, Zhang J, Chen JX, Nagashima M, Lundh ER, Vijay S, Nitecki D, et al: The receptor for advanced glycation end products (RAGE) is a cellular binding site for amphoterin. Mediation of neurite outgrowth and co-expression of rage and amphoterin in the developing nervous system. J Biol Chem 270: 25752-25761, 1995.

21. Park JS, Svetkauskaite D, He Q, Kim JY, Strassheim D, Ishizaka A and Abraham E: Involvement of Toll-like receptors 2 and 4 in cellular activation by high mobility group box 1 protein. J Biol Chem 279: 7370-7377, 2004.

22. Deng Y, Yang Z, Gao Y, Xu H, Zheng B, Jiang M, Xu J, He Z and Wang X: Toll-like receptor 4 mediates acute lung injury induced by high mobility group box-1. PLoS One 8: e64375, 2013.

23. Li Y, Zhou ZG, Xia QJ, Zhang J, Li HG, Cao GQ, Wang R, Lu YL and $\mathrm{Hu}$ TZ: Toll-like receptor 4 detected in exocrine pancreas and the change of expression in cerulein-induced pancreatitis. Pancreas 30: 375-381, 2005.

24. Dawra R, Sharif R, Phillips P, Dudeja V, Dhaulakhandi D and Saluja AK: Development of a new mouse model of acute pancreatitis induced by administration of L-arginine. Am J Physiol Gastrointest Liver Physiol 292: G1009-G1018, 2007.

25. Schmidt J, Lewandrowsi K, Warshaw AL, Compton CC and Rattner DW: Morphometric characteristics and homogeneity of a new model of acute pancreatitis in the rat. Int J Pancreatol 12: 41-51, 1992.

26. Pozsar J, Berger Z, Simon K, Kovacsai A, Marosi E and Pap A: Biphasic effect of prostaglandin E1 on the severity of acute pancreatitis induced by a closed duodenal loop in rats. Pancreas 12: 159-164, 1996.

27. Wang Y, Guo W, Li Y, Pan X, Lv W, Cui L, Li C, Wang Y, Yan S, Zhang J and Liu B: Hypothermia induced by adenosine 5'-monophosphate attenuates injury in an L-arginine-induced acute pancreatitis rat model. J Gastroenterol Hepatol 29: 742-748, 2014.

28. Jamdar S, Babu BI, Nirmalan M, Jeziorska M, McMahon RF and Siriwardena AK: Administration of human recombinant activated protein $\mathrm{C}$ is not associated with pancreatic parenchymal haemorrhage in L-arginine-induced experimental acute pancreatitis. JOP 14: 610-617, 2013.

29. Yenicerioglu A, Cetinkaya Z, Girgin M, Ustundag B, Ozercan IH, Ayten R, Kanat BH: Effects of trimetazidine in acute pancreatitis induced by L-arginine. Can J Surg 56: 175-179, 2013.

30. Chung KY, Park JJ and Kim YS: The role of high-mobility group box-1 in renal ischemia and reperfusion injury and the effect of ethyl pyruvate. Transplant Proc 40: 2136-2138, 2008.

31. Yang H, Ochani M, Li J, Qiang X, Tanovic M, Harris HE, Susarla SM, Ulloa L, Wang H, DiRaimo R, et al: Reversing established sepsis with antagonists of endogenous high-mobility group box 1. Proc Natl Acad Sci USA 101: 296-301, 2004. 
32. Kokkola R, Li J, Sundberg E, Aveberger AC, Palmblad K, Yang H, Tracey KJ, Andersson U and Harris HE: Successful treatment of collagen-induced arthritis in mice and rats by targeting extracellular high mobility group box chromosomal protein 1 activity. Arthritis Rheum 48: 2052-2058, 2003.

33. Andrassy M, Volz HC, Igwe JC, Funke B, Eichberger SN, Kaya Z, Buss S, Autschbach F, Pleger ST, Lukic IK, et al: High-mobility group box-1 in ischemia-reperfusion injury of the heart. Circulation 117: 3216-3226, 2008.

34. Kong X, Yuan H, Wu X, Zhang J, Zhou H, Wang M, Liu Y and Jin X: High-mobility-group box protein $1 \mathrm{~A}$ box reduces development of sodium laurate-induced thromboangiitis obliterans in rats. J Vasc Surg 57: 194-204, 2013.

35. Kohno T, Anzai T, Kaneko H, Sugano Y, Shimizu H, Shimoda M, Miyasho T, Okamoto M, Yokota H, Yamada S, et al: High-mobility group box 1 protein blockade suppresses development of abdominal aortic aneurysm. J Cardiol 59: 299-306, 2012.

36. Ueno H, Matsuda T, Hashimoto S, Amaya F, Kitamura Y, Tanaka M, Kobayashi A, Maruyama I, Yamada S, Hasegawa $\mathrm{N}$, et al: Contributions of high mobility group box protein in experimental and clinical acute lung injury. Am J Respir Crit Care Med 170: 1310-1316, 2004.

37. Kang R, Zhang Q, Hou W, Yan Z, Chen R, Bonaroti J, Bansal P, Billiar TR, Tsung A, Wang Q, et al: Intracellular Hmgbl inhibits inflammatory nucleosome release and limits acute pancreatitis in mice. Gastroenterology 146: 1097-1107, 2014.

38. Lange SS, Mitchell DL and Vasquez KM: High mobility group protein B1 enhances DNA repair and chromatin modification after DNA damage. Proc Natl Acad Sci USA 105: 10320-10325, 2008.

39. Kawase T, Sato K, Ueda T and Yoshida M: Distinct domains in HMGB1 are involved in specific intramolecular and nucleosomal interactions. Biochemistry 47: 13991-13996, 2008.
40. Cato L, Stott K, Watson M and Thomas JO: The interaction of HMGB1 and linker histones occurs through their acidic and basic tails. J Mol Biol 384: 1262-1272, 2008.

41. Giavara S, Kosmidou E, Hande MP, Bianchi ME, Morgan A, d'Adda di Fagagna $F$ and Jackson SP: Yeast Nhp6A/B and mammalian Hmgb1 facilitate the maintenance of genome stability. Curr Biol 15: 68-72, 2005.

42. Celona B, Weiner A, Di Felice F, Mancuso FM, Cesarini E, Rossi RL, Gregory L, Baban D, Rossetti G, Grianti P, et al: Substantial histone reduction modulates genomewide nucleosomal occupancy and global transcriptional output. PLoS Biol 9: e1001086, 2011.

43. Bonaldi T, Längst G, Strohner R, Becker PB and Bianchi ME: The DNA chaperone HMGB1 facilitates ACF/CHRAC-dependent nucleosome sliding. EMBO J 21: 6865-6873, 2002.

44. Covert MW, Leung TH, Gaston JE and Baltimore D: Achieving stability of lipopolysaccharide-induced NF-kappaB activation. Science 309: 1854-1857, 2005.

45. Yang H, Hreggvidsdottir HS, Palmblad K, Wang H, Ochani M, Li J, Lu B, Chavan S, Rosas-Ballina M, Al-Abed Y, et al: A critical cysteine is required for HMGB1 binding to Toll-like receptor 4 and activation of macrophage cytokine release. Proc Natl Acad Sci USA 107: 11942-11947, 2010.

46. Dobrovolskaia MA, Medvedev AE, Thomas KE, Cuesta N, Toshchakov V, Ren T, Cody MJ, Michalek SM, Rice NR, Vogel SN: Induction of in vitro reprogramming by Toll-like receptor (TLR)2 and TLR4 agonists in murine macrophages: effects of TLR 'homotolerance' versus 'heterotolerance' on NF-kappa B signaling pathway components. J Immunol 170: 508-519, 2003. 